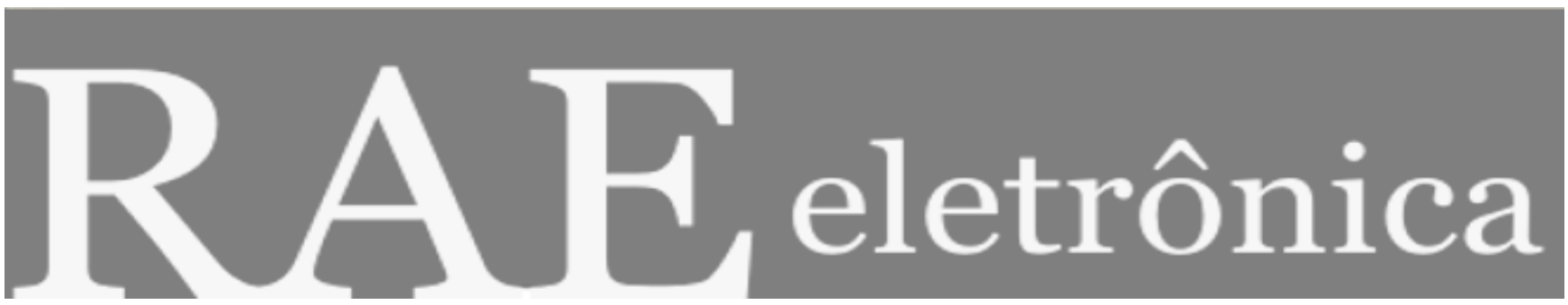

\title{
THE ELUSIVE QUEST FOR GROWTH: ECONOMISTS' ADVENTURES AND MISADVENTURES IN THE TROPICS
}

\author{
Por \\ Gilmar Masiero
}

RAE-eletrônica, Volume 2, Número 1, jan-jun/2003.

http://www.rae.com.br/eletronica/index.cfm?FuseAction=Artigo \&ID=1885\&Secao=RESENHAS\&Volume=2\&Numero=1 $\& \mathrm{Ano}=2003$

CCopyright, 2002, RAE-eletrônica. Todos os direitos, inclusive de tradução, são reservados. É permitido citar parte de artigos sem autorização prévia desde que seja identificada a fonte. A reprodução total de artigos é proibida. Os artigos só devem ser usados para uso pessoal e nãocomercial. Em caso de dúvidas, consulte a redação: redacao@,rae.com.br.

A RAE-eletrônica é a revista on-line da FGV-EAESP, totalmente aberta e criada com o objetivo de agilizar a veiculação de trabalhos inéditos. Lançada em janeiro de 2002, com perfil acadêmico, é dedicada a professores, pesquisadores e estudantes. Para mais informações consulte o site www.rae.com.br/eletronica.

RAE-eletrônica

ISSN 1676-5648

(C)2002 Editora: Fundação Getulio Vargas - Escola de Administração de Empresas de São Paulo.

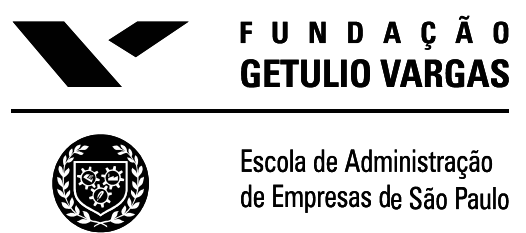




\section{THE ELUSIVE QUEST FOR GROWTH: ECONOMISTS' ADVENTURES AND MISADVENTURES IN THE TROPICS}

Por Gilmar Masiero.

Professor da Universidade Estadual de Maringá.

E-mail: g_masiero@yahoo.com

The Elusive Quest for Growth: Economists' Adventures and Misadventures in the Tropics De Easterly, William.

Cambridge: MIT, 2001. 342p

Pessoas respondem a incentivos, este é o argumento central de William Easterly em The Elusive Quest for Growth. Da mesma forma que Globalization and its Discontents, de seu antigo colega no Banco Mundial, Joseph Stiglitz, este livro desafia as visões prévias sobre o papel das instituições financeiras internacionais e as políticas voltadas para o desenvolvimento. O argumento central do livro, e porque ele permanece The Elusive Quest for Growth, é que as instituições financeiras internacionais (IFI) têm promovido políticas que falharam devido a sua resistência em atrelar ajuda a incentivos.

Seguindo os modelos teóricos desenvolvidos pelo economista Paul Romer, da Universidade de Stanford, Easterly descreve o crescimento econômico como sendo induzido por investimentos diretos em conhecimentos, que, contrariamente aos investimentos em capital físico, possuem retornos crescentes. Devido a esta propriedade, a criação de conhecimento possui efeitos espirais para o resto da economia e conduz a um circulo virtuoso de maiores retornos e crescimento econômico. Pessoas bemeducadas, com acesso a recursos financeiros, tecnologia e conhecimento - alguns dos principais ingredientes para o crescimento econômico -, tendem a se congregar com semelhantes e aprender com eles. O mesmo fenômeno se repete para os pobres que possuem menor acesso a recursos financeiros, tecnológicos e de conhecimento e que se congregam entre si. Conseqüentemente, as oportunidades de aprendizagem, investimento e crescimento econômico para estes são menores.

Em sua totalidade, o livro é uma legítima descrição dos fracassos dos economistas em lidarem com a temática do crescimento econômico no Terceiro Mundo, ou, como menciona o título, nos Trópicos. No início dos anos 80, o Banco Mundial, o FMI e outras instituições multilaterais lançaram um grande número de programas de "ajustes estruturais" especialmente desenhados para suportar a adoção de políticas que conduziram a "inesperadas?" crises financeiras. Estas regras, universalmente impostas, e os formais modelos matemáticos que subsidiam as análises macroeconômicas das IFIs, são construídas a partir de duas falsas pressuposições, corretamente apontadas por Easterly.

A primeira, é que investimentos induzem o crescimento. Estatísticas demonstram que isto somente é verdade naqueles poucos casos onde os mesmos são realizados em conjunto com apropriada tecnologia, conhecimento e um saudável ambiente político e econômico. A segunda pressuposição errada diz que a ajuda externa aumenta o investimento. Várias análises demonstram que a maioria dos governos simplesmente consome, ao invés de investir, a ajuda recebida. $\mathrm{O}$ mais interessante destas duas evidências paradigmáticas errôneas paradigmáticas do desenvolvimento é que as IFIs continuam as utilizando, mesmo sabendo que não funcionam. 
The Elusive Quest for Growth demonstra que, nem anistia da divida, nem ajuda, tem provado ser a resposta para o desenvolvimento em países com maus governos. William Easterly aponta que no Terceiro Mundo os governos freqüentemente têm adotado políticas destrutivas uma vez que agem privilegiadamente no interesse de grupos étnicos ou classes sociais e não no interesse da nação como um todo. Seguindo esta lógica, Easterly argumenta que para financiar seu atual padrão de vida (principalmente da clientela governamental) os paises do Terceiro Mundo se endividaram fortemente, comprometendo o futuro das próximas gerações. Além de incorrer em dividas elevadas, ele diz que governos irresponsáveis venderam patrimônios nacionais (óleo, diamantes, florestas, empresas estatais etc.) para viver bem ao mesmo tempo em que sua população permanecia pobre.

Easterly visualiza um Terceiro Mundo onde os governos providenciam a infraestrutura nacional clínicas de saúde, escolas primárias e estradas bem preservadas - e assistência aos pobres. Coisas como alta inflação, mercados negros, corrupção, juros elevados, déficits orçamentários, restrições ao livre comércio e péssimos serviços públicos, criam fracos incentivos para o crescimento. Ele acredita que democracia, regras legais, bancos centrais independentes e outras instituições qualificadas são necessárias para parar o infinito ciclo de más políticas que perpetuam o fraco crescimento. $\mathrm{O}$ Banco Mundial, o FMI e outros órgãos doadores devem disponibilizar ajuda aos governos que apresentem confiáveis intenções de construir a infraestrutura nacional, e de direcioná-la para onde será mais efetiva para os pobres.

Embora o autor esteja certo no que diz respeito aos governantes do Terceiro Mundo não necessariamente terem atuado no interesse da presente e futura geração, Easterly não explica os incentivos que motivam as IFIs a continuar ajudando e desenvolvendo projetos no Terceiro Mundo. Easterly, por exemplo, não considera quais são os incentivos que motivam as IFIs, que em grande parte são administradas pelas nações desenvolvidas, na escolha e ênfase de programas e prescrições particulares. No caso das recentes privatizações, países desenvolvidos efetivamente exerceram pressão sobre as IFIs na defesa de seus próprios interesses (e daqueles dos investidores privados) para a venda de ativos de maneira que fossem comprados por investidores e gerentes "mais responsáveis" do Primeiro Mundo.

Para alguns, o livro parecerá simplista porque o autor re-enfatiza a singularidade do crescimento econômico como a panacéia para aliviar a pobreza. Embora o crescimento econômico seja uma condição necessária para aliviar a pobreza, ele não é uma condição suficiente. Easterly endereça suas recomendações a três atores: governos, agências internacionais de desenvolvimento e indivíduos. No entanto, não menciona qual seria o papel das grandes empresas e do sistema político e institucional como outros atores importantes. Ele tem pouca coisa a dizer sobre o que o Banco Mundial tem feito. É o Banco Mundial uma instituição necessária?

Após ler The Elusive Quest for Growth, a principal questão que surge é por que economistas internacionais renomados, como Easterly, o Prêmio Nobel Joseph Stiglitz, ou outros, não foram capazes de reconhecer, previamente, as falhas dos modelos de desenvolvimento econômico? Se os economistas não foram capazes de reconhecer simples falhas apontadas por Easterly, cabe a dúvida se devemos acreditar que "novos incentivos baseados no crescimento", propostos por ele, funcionarão. Devemos acreditar que atualmente "estamos numa melhor posição que nossos predecessores para fazer o modelo funcionar por duas razões: agora temos quatro décadas de experiência para verificar o que funcionou e não funcionou, e que a profissão de economista tem feito alguns progressos no desenvolvimento de ferramentas analíticas que fornecem insights sobre o crescimento econômico"? (p.144). 